\title{
RHUSMOS E MOVIMENTO DOS ÁTOMOS NA FÍSICA DE DEMÓCRITO
}

\author{
Miriam Campolina Diniz Peixoto* \\ mcdpeixotobh@gmail.com
}

RESUMO A noção de rhusmos ocupa um lugar central na física atomista, e a explicação do papel que desempenha na economia da descrição dos átomos $e$ de seu movimento é bastante importante quando se quer compreender a novidade da doutrina atomista no seio das cosmologias pré-platônicas. $\mathrm{Na}$ célebre passagem do livro A da Metafísica (A, IV, 985 b 14-17), Aristóteles, ao precisar o papel fundamental desempenhado pela diferença entre os átomos na explicação das diferenças qualitativas constatadas nos corpos compostos, escreve: "Estas diferenças, eles [os atomistas] dizem, são três: a forma, a ordem e a posição. As diferenças do ser, dizem eles, não vêem senão do rhusmos, da disposição e do lugar. Ora o rhusmos, é a forma, a disposição é a ordem, e o lugar é a posição." É, pois, por intermédio de seus rhusmoi, sua disposição e seu lugar que se explica os diferentes compostos atomicos e suas diferentes disposições à mudança e ao movimento. Quando Aristóteles substitui rhusmos por skhêma, ele privilegia um aspecto da realidade: sua determinação formal e estática. Assim fazendo, ele deixa de lado um aspecto ainda mais determinante da natureza do átomo - pois é graças a ele que os corpos compostos são engendrados -, presente na noção de rhusmos: o fato que os átomos se encontram sempre em movimento, o que lhes permite se ordenarem em sempre novas configurações. Trata-se, pois, de precisar o que é o rhusmos e qual é o seu papel na explicação do movimento dos átomos.

* Professora do Departamento de Filosofia da UFMG. Recebido em 28/01/2010 e aprovado em 02/03/2010.

KRITERION, Belo Horizonte, nº 122, Dez./2010, p. 413-428. 
Palavras-chave Demócrito, Aristóteles, Atomismo, rhusmos, movimento, Física.

ABSTRACT The concept of rhusmos occupies a central position in atomistic physics and the explanation for the role that it plays in the economy of the description of atoms and their movement is rather important when one wants to understand the innovation of atomistic doctrines in the context of pre-platonic cosmologies. In the famous passage of the first book of Metaphysics (A, IV, 985 B 14-17), Aristotle, as he specifies the fundamental part played by the difference between atoms in order to explain qualitative differences noted in atomic compounds, writes: "These differences, they say [the Atomists], are three : shape, order and position. They say reality is differentiated only by 'rhusmos' and 'inter-contact' and 'turning'; and of these rhusmos is shape, inter-contact is order and turning is position. "It is, therefore, by means of the their rhusmoi, inter-contact and turning that the variety of atomic compounds and their different dispositions to change and movement are explained. When Aristotle replaces rhusmos by skhêma (shape), it privileges one aspect of reality: its formal and static determination. By doing so, he neglects an even more determining aspect of the nature of atom-since it is the reason why compound bodies are generated -, which is present in the concept of rhusmos, i.e. the fact that they are always moving, which allows them to reorganize themselves in ever new configurations. Therefore the issue is to specify what rhusmos is and the role that it plays in the explanation of the movement of atoms.

Keywords Democritus, Aristotle, Atomism, rhusmos, movement, Physics.

A noção de rhusmos ocupa um espaço importante na física atomista, particularmente na descrição dos átomos e de seu movimento. Na célebre passagem do livro A da Metafísica (A, IV, 985 b 14-17), Aristóteles testemunha acerca do papel fundamental desempenhado pela diferença entre os átomos na explicação das diferenças qualitativas constatadas nos corpos compostos:

Ora estas diferenças são, segundo eles [os atomistas], em número de três: a forma, a ordem e a posição (tautas mentoi treis einai legousi, skhêma te kai taxin kai thesin). As diferenças do ser, dizem eles, não vêem senão do rhusmos, da disposição e do 
lugar (diapherein gar phasi to on rhusmoi kai diathigê kai tropê monon). Ora o rhusmos, é a forma, a disposição é a ordem, e o lugar é a posição (toutôn de ho men rhusmos skhêma estin he de diathigê taxis de tropê thesis).

É por intermédio dos rhusmoi dos átomos, de sua disposição e lugar nos compostos que se explica, não apenas a existência de diferentes compostos atômicos, mas, também, os diferentes tipos de movimento. Trata-se, pois, de precisar o sentido exato do termo nos fragmentos e testemunhos de que dispomos, tarefa que se mostra indispensável quando se quer compreender a natureza dos átomos e dos seus movimentos no vazio e nos compostos atômicos. Os comentadores modernos se esforçaram, por caminhos diversos em oferecer uma definição de rhusmos e em compreender o papel particular desta noção na física atomista. Nós pretendemos, neste artigo, verificar o estado da questão e avançar algumas interpretações sobre o tema.

Segundo Demócrito, existem substâncias em número infinito, aos quais chamou ideai, e, sobretudo a partir de Aristóteles e da tradição aristotélica se convencionou designar atomoi, dada a sua indivisibilidade, que se movem, dispersas no vazio infinito. "Quando se aproximam uma das outras, testemunha Plutarco, encontrando-se e combinando-se (ê sumpesôsin ê periplakôsi)" ou bem se aglomeram em corpos compostos mais simples como a água, o fogo, ou em mais complexos como os das árvores e dos homens. A essas substâncias, continua Plutarco, ele chamou "formas insecáveis (tas atomous ideas)", dizendo serem elas "impassíveis e imutáveis em razão de sua solidez (ek de tôn ontôn mêden na genesthai tôi mête paskhein mête metaballein tas atomous hupo sterrotêtos)"'.

Este testemunho de Plutarco apresenta em suas grandes linhas a física democritiana, suas substâncias elementares, princípios de todas as coisas, e o processo mediante o qual vêem a ser todas as coisas. Ao lado destas ideai, e como elas igualmente princípio e, logo, realidade eterna e infinita, postula o vazio/to kenon. A respeito do vazio, Aristóteles escreve na Física:

Aqueles, ao invés, que afirmam como sendo necessário o vazio (einai kenon hôs anankaion) acabam antes por chegar, se prestamos atenção ao que dizem, à conclusão contrária, isto é, que é impossível que algum ser possa se mover se existe o vazio ( $m e \hat{e}$ endekhesthai mede hen kineisthai, ean hêi kenon). ${ }^{2}$ 
Os átomos e o vazio constituem os princípios do universo. A estrutura do mundo é a mesma em cada um dos "pequenos mundos" existentes:

Se tudo isso pode acontecer no interior do animal, o que impediria que as mesmas coisas acontecessem no conjunto da realidade? Se isso acontece em um mundo pequeno (ei gar en mikrôi kosmôi ginetai), acontece também em um mundo grande (kai en megalôi)." (DK 68 B 34; L 10)3.

Trata-se, pois, de compreender como é possível que a partir de substâncias simples, ideai/atomoi, um universo tão variado pode vir a ser, em outras palavras, como coisas tão distintas como a água, as árvores e os homens puderam se constituir. Resumindo, como a partir de princípios, ao mesmo tempo múltiplos e simples, como os corpúsculos elementares, e infinito como o vazio, uma multiplicidade de "mundos" teve sua origem.

De um lado os átomos, de outro, o vazio. O vazio não é simplesmente um não átomo, um nada, mas uma extensão infinita que constitui o espaço onde os átomos se deslocam e que lhes permite se reunirem e dar origem a uma multiplicidade infinita e complexa de corpos compostos. É, pois, interrogandose acerca do que sejam os átomos que é possível alcançar uma compreensão da multiplicidade de corpos compostos e que a variedade e complexidade do universo pode encontrar sua explicação. Em uma conhecida passagem do livro A da Metafísica (A, IV, 985 b 14-17) Aristóteles precisa o papel fundamental desempenhado pela diferença entre os átomos na explicação das diferenças qualitativas constatadas nos corpos compostos:

Ora estas diferenças são, segundo eles [os atomistas], em número de três: a forma, a ordem e a posição (tautas mentoi treis einai legousi, skhêma te kai taxin kai thesin). As diferenças do ser, dizem eles, não vêem senão do rhusmos, do contato recíproco e da disposição a volver (diapherein gar phasi to hon rhusmôi kai diathigêi kai tropêi monon). Ora o rhusmos, é a forma, o contato recíproco é a ordem, e a disposição a volver é a posição (toutôn de ho men rhusmos skhêma estin hê de diathigê taxis hê de tropê thesis).

É, portanto, por meio do rhusmos, do contato recíproco e da disposição a volver os átomos em um corpo composto que é possível explicar a natureza particular de cada coisa e a dinâmica que lhe é própria. E o que vale para os corpos compostos na explicação de sua natureza singular e peculiar, serve também para explicar nele a mudança e o movimento, assim como a diversidade

3 ARISTÓTELES, Física, VIII 2, 252 b 24. Outros testemunhos atestam esta homologia: DAVID, Proleg. 38, 14 Busse; GALENO, De usu part. III 10 (III 241 K., I 177, 10 Helmr.) ; SEXTO EMPÍRICO. Adv. math. VII 116117. 
de movimentos dos átomos no vazio e nos compostos, bem como sua maior ou menor susceptibilidade a um ou outro tipo de movimento. Com efeito, estas três diferenças poderiam ser reduzidas a duas: uma diferença intrínseca, o rhusmos, que não concerne senão ao átomo individualmente considerado naquilo que o distingue de outros, e uma diferença extrínseca ou relacional, a disposição a girar e a entrelaçar e o contato recíproco, o que supõe a relação entre os átomos ${ }^{4}$.

Antes de prosseguirmos com nossa análise desta tese, gostaríamos de considerar o procedimento aristotélico de redução operado pela substituição dos termos democritianos. Compartilhamos, quanto a isso, a compreensão de M. L. Gemelli Marciano a este respeito:

Aristóteles traduz, portanto, em uma terminologia mais adequada aos problemas teóricos do atomismo do seu tempo os termos originais democritianos tendo como resultado uma transformação do átomo como corpo em movimento em uma entidade espacial abstrata (...) [ele] transforma o átomo em uma figura estática e abstrata nos moldes das figuras geométricas platônicas. ${ }^{5}$

Em outras palavras, a transposição que opera Aristóteles não é uma mera substituição de um termo por outro. Com efeito, observamos uma mudança significativa da concepção atomista na substituição de rhusmos por skhêma, de diathigê por taxis e de tropê por thesis. Sobre o termo rhusmos nos ocuparemos mais detidamente na sequência de nossa exposição. Ocupemo-nos, no momento, dos dois outros pares de quase-sinônimos. Como apontamos antes, cada um dos termos que propõe Aristóteles em substituição aos termos originais implica uma perda em termos do caráter dinâmico dos átomos. O termo tropê traz implícita a ideia de mudança e, no vocabulário da guerra, diz respeito ao movimento de fazer meia volta e retroceder diante do inimigo. Este é um dos sentidos principais com os quais o vemos empregado

4 Cf. Wismann, H., "Réalité et matière dans l'atomisme démocritéen", Siculorum Gymnasium, XXXIII, 1980, p. 61 - 74 (=Congrès de Catane, 1979) : "la 'forme' est susceptible d'être considérée comme une propriété intrinsèque de l'atome [individuel], tandis que l'ordre' et la 'position' supposent déjà une relation, un rapport avec le milieu où évoluent d'autres atomes. " (p. 69), e SAUVANET, P., Le rythme grec d'Héraclite à Aristote. Paris : PUF, 1999: "Par rapport aux deux autres modalités du texte, le rythme apparait comme une donnée intrinsèque: sur l'exemple choisi, la différence entre $A$ et $\mathrm{N}$ est intrinsèque, tandis que la différence entre AN et NA (ordre) ou Z et N (position) est extrinsèque" (p. 42).

5 Gemelli Marciano, M. L., Democrito e l'Accademia. Studi sulla trasmissione dell'atomismo antico da Aristotele a Simplicio. Berlim/New York: Walter de Gruyter, 2007, p. 203-202. 
em Heródoto ${ }^{6}$, Tucídides 7 , trágicos ${ }^{8}$ e em Aristófanes 9 . A favor desta acepção temos ainda a sequência do fragmento democritiano em Aristóteles: "Estas essências estão em luta uma contra a outra e se movem no vazio por causa da sua desigualdade e das outras diferenças antes mencionadas e, movendo-se, se chocam e se entrelaçam...". As imagens destes choques e entrelaçamentos nos fazem pensar na stasis, a sedição ou guerra civil. Alguns átomos, ao se chocarem com outros, ricocheteiam e "partem em retirada". Outros se prendem uns aos outros. O contexto aqui é cosmogônico, como bem lembrou Gemelli Marciano: "neste caso a 'reviravolta' não comporta uma 'retirada', mas determina simplesmente um arranjo diverso do próprio composto: o corpo muda, por exemplo, de cor." ${ }^{\prime 10}$ Esta suscetibilidade a volver, a mudar, é enfraquecida pela adoção do termo thesis, que como sabemos, provém do verbo tithêmi, estabelecer, pôr, colocar, instituir, o que sugere algo estático. Aristóteles não apenas elimina seu aspecto dinâmico e o caráter relacional do termo desta "disposição a volver" em face do outro, como apaga as imagens e conotações sócio-políticas presentes em tropê.

Se alguns átomos ao se encontrarem com outros partem em retirada, outros vão se entrelaçando nestes embates, ficando "aprisionados", abraçados ou envolvidos, adaptando-se a esta circunstância, sem, contudo se fundirem uns aos outros numa "união completa" 1 . A este processo de "contato recíproco" Demócrito deu o nome de diathigê, o qual Aristóteles substituiu pelo termo taxis. Derivado do verbo thinganô que significa não apenas "tocar", mas, também, "abraçar" 12 e ter relações sexuais, o termo diathigê se refere, também, a uma espécie de luta em que os contatos sendo forçados podem se transformar em força capaz de engendrar. Ao substituir o termo por taxis, ordem dos átomos em um composto, mais uma vez Aristóteles altera o sentido original, eliminando, desta vez, o caráter de reciprocidade e o dinamismo que dele decorre. Temos aqui uma redução matemática que se afasta da perspectiva física em que se inscreve a reflexão atomista de Demócrito e Leucipo. Do

6 HERODOTO, Hist 1.30.24: teleutê biou lamprotatê epegeneto: genomenês gar Athênaioisi makhês pros tous astugeitonas en Eleusini boêthêsas kai tropên poiêsas tôn polemiôn apethane kallista, kai min Athênaioi dêmosiêi te ethapsan autous têi per epese kai etimêsan megalôs.

7 TUCIDIDES, Guerra do Peloponeso, 2.19.2.1-4: kai kathezomenoi etemnon prôton men Eleusina kai to Thriasion pedion kai tropên tina tôn Athênaiôn peri tous Rheitous kaloumenous epoiêsanto (...).

8 ÉSQUILO, Agamemnon, 1236-1237: hôs d'epôloluxato hê pantotomos, hôsper en makhês tropêi; EURÍPEDES, Rhesus, 82: oud'hôde g'aiskhrôs epeson en tropêi doros.

9 ARISTOFANES, Equestre, Eq 246: All'amunou kai diôke kai tropên autou poiou.

10 Gemelli Marciano, M. L., Op. cit., p. 204.

11 A expressão é de M. L. Gemelli Marciano, Op. cit., p. 204.

12 Encontramos o termo empregado neste sentido, por exemplo, no verso 300 das Fenícias e nos versos 885 e 1044 do Hipólito de Eurípedes, e no verso 329 do Édipo em Colono de Sófocles. 
mesmo tipo de redução foi objeto o termo rhusmos ao dar lugar ao termo skhêma.

\section{O rhusmos}

Para precisar em que consiste o rhusmos dos átomos constitutivos dos corpos, nós podemos nos apoiar em uma série de testemunhos e fragmentos provenientes da obra de Aristóteles, mas, também, de fontes de outras tradições.

O que nos interessa, num primeiro momento, é saber o que determina a aglomeração dos corpos primordiais nos corpos compostos ou secundários, e, num segundo momento, sua relação com o tipo de movimento que se percebe em um determinado composto. Quando Aristóteles substitui rhusmos por skhêma, ele privilegia um aspecto da realidade, sua determinação formal, deixando de lado outro aspecto, ainda mais fundamental da natureza do átomo - pois é graças a ele que os corpos compostos são engendrados e variados -, aquele compreendido na noção de rhusmos: o fato dos átomos se encontrarem sempre em movimento, o que lhes possibilita se ordenarem em sempre novas configurações ${ }^{13}$. Mas o que é, afinal, o rhusmos de um átomo?

A importância deste termo no âmbito da cosmologia e da física atomistas pode ser atestada já no exame do catálogo de Trasilo que nos transmitiu Diógenes Laércio: entre os livros sobre a natureza, se encontram os seguintes títulos: Sobre os diferentes rhusmoi/Peri ton diapherontôn rhusmôn e Sobre as alternâncias de rhusmoi/Peri ameipsirhusmiôn, e entre os livros sobre música o título Sobre os ritmos ${ }^{14}$ e a harmonia/Peri rhuthmôn kai harmoniês. Precisar o sentido exato do termo nos testemunhos e fragmentos de que dispomos se mostra, apesar das dificuldades de interpretação, indispensável quando se trata de compreender o que permite distinguir os átomos em sua singularidade e nos compostos. Um debate animado envolveu os comentadores e intérpretes modernos em seu esforço para oferecer uma definição do termo rhusmos e compreender seu papel particular na economia da filosofia atomista. O debate se faz ainda mais animado porque as dificuldades que o suscitaram remontam às fontes mesmas a que recorremos para conhecer a filosofia dos antigos atomistas.

Faz-se ainda mais necessário compreender o termo rhusmos quando se constata o emprego múltiplo, mas uniforme, que dele faz Demócrito, seja no contexto da física e da cosmologia, seja naquele de seus fragmentos éticos. A 
título de exemplo, mencionamos dois deles que analisaremos posteriormente. O primeiro nos foi conservado na obra de Clemente de Alexandria:

Natureza e educação são coisas bastante semelhantes (hê phusis kai hê didakhê paraplêsion). Pois é verdade que a educação transforma o homem (kai gar hê didakhê metarhusmoi ton anthrôpon), e esta transformação produz natureza (metarhusmousa de phusiopoiei). ${ }^{15}$

Neste fragmento temos o termo rhusmos precedido do prefixo verbal meta- no verbo metarrhuthmizo ${ }^{16}$, aqui presente em dialeto jônio ${ }^{17}$. É, pois, a própria estrutura do homem, sua natureza, que será transformada pela educação. Transformação esta que é explicada neste contexto por um outro verbo de criação democritiana, phusiopoiein, "produzir natureza". Ora, se a natureza de alguma coisa concerne sua estrutura atômica, é a disposição dos átomos no composto que padece a mudança. Essa disposição à mudança explica, de resto, o fato que a natureza humana pode ser modificada, que ela pode se tornar outra sem perder sua identidade.

15 CLEMENTE DE ALEXANDRIA, Stromata IV, 151 : DK 68 B 33.

16 Cf. Montanari, F., Vocabolario della Lingua Greca. Turin: Loescher Editore, 1996, p. 2193, Col. 3, que indica justamente este fragmento de Demócrito como exemplo do emprego deste verbo. O verbo aparece, também, ainda no século V, nos Econômicos de Xenofonte, 11.16-17: epeidan de elthô eis agron, an te moi phuteuontes tunkhanôsin an te neiopoiountes an te speirontes an te karpon proskomizontes, tauta episkepsamenos hopôs hekasta gignetai, metarrhuthmizô, ean ekhô ti beltion tou parontos. No século IV, temos uma única ocorrência do termo em Teofrasto, em As Causas das Plantas. O curioso é que ele emprega o termo em um contexto em que se refere a Demócrito: Dê. Aqui nós conservamos o termo ritmo porque nos encontramos no contexto da música.

CLEMENTE DE ALEXANDRIA, Stromata IV, 151: DK 68 B 33.

Cf. Montanari, F., Vocabolario della Lingua Greca. Turin: Loescher Editore, 1996, p. 2193, Col. 3, que indica justamente este fragmento de Demócrito como exemplo do emprego deste verbo. O verbo aparece, também, ainda no século V, nos Econômicos de Xenofonte, 11.16-17: epeidan de elthô eis agron, an te moi phuteuontes tunkhanôsin an te neiopoiountes an te speirontes an te karpon proskomizontes, tauta episkepsamenos hopôs hekasta gignetai, metarrhuthmizô, ean ekhô ti beltion tou parontos. No século IV, temos uma única ocorrência do termo em Teofrasto, em As Causas das Plantas. O mokritôi men Ge pôs pote ex allêlôn hê genesis aporêseien an tis. Anankhê gar ê ta skhêmata metarrhuthmizesthai kai ek skalênôn kai oxugôniôn peripherê ginesthai, ê pantôn enuparkhontôn tôn te tou struphnou kai oxeos kai glukeos ta men ekkrinesthai ta tôn proteron aei thatera de hupomenein ta oikeia kath' hekaston, ê triton ta men exienai ta d'epeisienai. (6.7.2.1-8) O termo parece ter sido um neologismo democritiano.

17 De certa maneira, acrescentar o prefixo meta- ao radical de rhusmos reforça a ideia de movimento, mas isso poderia soar também como um pleonasmo, pois rhusmos que comporta já este aspecto, poderia bastar a exprimir a nuance em questão. 
Um outro fragmento, desta vez do Léxico de Hesíquio ${ }^{18}$, o confirma: "ameipsirhusmein (alternar os rhusmoi): mudar $<$ no que concerne $>$ a mistura, ou mudar de forma (metamorphousthai)"19.

A relação "alternar os rhusmoi", "mudar de forma", atestada por Hesíquio sugere qual teria sido o tema da obra a que se faz referencia em DK 68 B 8a : PERI AMEIPSIRHUSMIÔN/Sobre a alternância dos rhusmoi. Examinemos, primeiramente, as observações de E. Benveniste em seu artigo "La notion de 'rythme' dans son expression linguistique" 20 .

\section{A interpretação de E. Benveniste para o termo rhusmos}

A maior parte dos dicionários sustenta que rhusmos/rhuthmos é o abstrato de rhein, "fluir". Boisacq pensa que o sentido do termo tenha sido "tomado de empréstimo ao movimento regular das águas" (p. 327).

Para E. Benveniste não é difícil, do ponto de vista morfológico, ligar rhuthmos a rheô, ao contrário a pretendida ligação semântica entre "ritmo" e "cor" por meio do "movimento regular das águas" lhe parece improvável à primeira vista. Escreve Benveniste: "nunca rhein se diz do mar, e, além disso, rhuthmos nunca é empregado para o movimento das águas" (p. 328). Termo ausente dos poemas homéricos, rhuthmos aparece nos autores jônios e na poesia lírica, assim como na prosa ática e nos filósofos. Nos poetas líricos o termo é atestado desde o século VII com o sentido de skhêma ou de tropos, e serve a definir a "forma" individual e distintiva do caráter humano (Arquíloco, II, 400, Bergk), as "formas" particulares do humo ou do caráter (Anacreonte, fr. 74, 2), ou ainda os traços distintivos do homem (Teógnis, 964) (p. 330). Nos poetas trágicos o termo e os verbos derivados conservam este sentido. $\mathrm{O}$ autor retém uma passagem em particular. Trata-se do verso 318 da Antígona de Sófocles, em que, em resposta a uma questão posta pelo guardião - "é nas

18 Hesíquio de Alexandria compôs o seu Léxico no século V ou VI d.C., reunindo palavras cujo sentido era considerado obscuro. Ele baseou seu trabalho em um léxico mais antigo, aquele de Diogeniano, provavelmente do século II a.C.. O trabalho de Hesíquio consiste em uma lista de termos poéticos e dialetais, frases e pequenos provérbios, e se apresenta como os nossos modernos dicionários. Ele constitui a única fonte para um grande número de termos raros. O único manuscrito conservado deste léxico se encontra bastante e seriamente corrompido. A melhor edição disponível é aquela de $L$. Latte (1953-66=TLG) e de P. Hansen (2005), mas ela contém somente os termos de $A-S$. Para o resto do alfabeto o texto padrão é a editio maior de Moritz Schmidt (1858-68=TLG), que compreende o conjunto do alfabeto, mas é bastante diferente da de Latte. Cf. DICKEY, E., Ancient Greek Scholarship. A Guide to Finding, Reading, and Understanding Scholia, Commentaries, Lexica, and Grammatical Treatises, from Their Beginnings to the Byzantine Period. Col. "American Philological Association". Oxford/New York: Oxford University Press, 2007, p. 88-90.

19 HESIQUIO, Léxico; 68 B 139 DK.

20 Benveniste, E., Problèmes de linguistique générale. Paris: Gallimard, 1966. 
orelhas ou em tuas almas que minha voz lhe faz sofrer?" - Creonte responde: "a que serve lhe figurar a localização de minha dor (ti de rhuthmizeis tên emên lupên hopou)?".

De acordo com Benveniste este é precisamente o sentido de rhuthmizô, "dar uma forma". Em Eurípides, o emprego de termos derivados permite melhor precisar o sentido. Ele emprega o termo eurhuthmôs, designando por ele "uma maneira conveniente" de realizar uma certa ação (Cycl., 563) e o termo arrhuthmos, para se referir a uma paixão "desproporcional" (Hipp., 529). O mesmo se passa com a prosa atica do século V. Xenofonte se refere com eurhuthmos à qualidade de bela couraça (Mem., III, 10, 10), e para Platão rhuthmos quer dizer a "disposição proporcional" entre a opulência e o desnudamento (Leis, 728 e).

Mas é no vocabulário da filosofia jônica que nos podemos captar melhor o valor específico de rhusmos, e particularmente em Leucipo e Demócrito. Como observou P. Sauvanet ${ }^{21}$ "podemos situar nos atomistas a verdadeira data de nascimento do conceito de ritmo em filosofia". Constatação que já se encontrava presente em E. Benveniste: "Estes filósofos fizeram de rhuthmos (rhusmos) ${ }^{22}$, um termo técnico, uma das palavras chaves de sua doutrina, e Aristóteles, graças a quem chegaram até nós muitas citações de Demócrito, nos transmitiu sua significação exata" ${ }^{23}$. Trata-se da equivalência que estabelece Aristóteles entre skhêma e rhusmos na passagem que antes examinamos da Metafísica (A, 4, 985 b 14-17). Como podemos constatar, para E. Benveniste, é sempre no sentido de forma que Demócrito o emprega; a forma dos átomos, como na passagem em questão, mas também a forma das instituições como no fragmento conservado por Estobeu: "não existe nenhuma disposição na forma atual < das leis $>$ que impeça que alguém faça mal aos magistrados (...)"24. Parece, segundo ele, ser também este o sentido dos verbos rhusmô, metarrhusmô, metarrhusmizộ no âmbito da física e da ética: "os espíritos insensatos são transformados pelos ganhos da fortuna, mas os homens de experiência por aqueles da sabedoria"25; "a educação transforma o homem"26; "é preciso que os skhêmata mudem de forma (para passar de angulosos ao

21 Sauvanet, P., Le Rythme grec d'Héraclite à Aristote. Paris: PUF, 1999, p. 39.

22 O termo se encontra grafado em uma ou outra destas formas. Trata-se de uma variaçao dialetal.

23 Benveniste, E., Op. cit., p. 328.

24 ESTOBEU, Florilégio, IV, V, 48: 68 B 266 DK: oudemia mêkhanê tôi nun kathestôti rhuthmôi mê ouk adikein tous arkhontas.

25 ESTOBEU, Florilégio, III, IV, 71: 68 B 197 DK: anoêmones rhusmountai tois tês tukhês kerdesin $\square$ hoi de tôn toiônde daêmones tois tês sophiês.

26 CLEMENTE DE ALEXANDRIA, Stromata, IV, 151: 68 B 33 DK: hê didakhê metarhusmoi ton anthrôpon (...). 
redondo)"27. Demócrito emprega ainda o adjetivo epirrhusmios no sentido de "dotado de uma forma", ao contrário do que pensaram Bailly ("courant, que se répand") e Liddell-Scott ("adventitions"): "nós não conhecemos nada autenticamente sobre nada, mas cada um da forma à sua crença" 28 .

Essas indicações levam E. Benveniste a reconhecer que não existe "nenhuma ambiguidade" no emprego de rhusmos em Demócrito, que seu sentido estará sempre associado àquele de "forma distintiva", ou de "arranjo característico das partes em um todo" ${ }^{29}$. E esse sentido pode se confirmar, segundo ele, também para a totalidade dos exemplos antigos. Em razão do que ele conclui “1) que rhuthmos não significa nunca 'ritmo' desde a origem até o período ático; 2) que ele nunca é aplicado ao movimento regular das águas; 3) que o sentido constante é o de 'forma' distintiva; figura proporcionada; disposição". ${ }^{30}$ E justifica sua objeção dizendo que ela não se deve à variação ela mesma (rheôrhuthmos), "mas ao sentido inexato de rhuthmos que dela foi deduzido".

Sua análise toma uma direção que nos parece particularmente interessante. Examinando a formação das palavras em - (th)mos, e o sentido que este sufixo confere aos termos abstratos, ele constata que ele não indica a "a realização da noção, mas a modalidade particular de sua realização, tal que ela se apresenta aos olhos"31. Como exemplos cita: "orkhêsisé o fato de dançar, orkhêthmos a dança particular vista em seu desenrolar; khrêsis é o fato de consultar um oráculo, khrêsmos a resposta particular obtida do deus; thesis é o fato de pôr, thesmos a disposição particular; stasis é o fato de deter, stathmos a maneira de se deter, donde: equilíbrio de uma balança ou parada ocasional". Mas, se E. Benveniste reduz rhusmos a forma, como fica a associação de rhusmos à skhêma.

E. Benveniste estabelece uma distinção os dois termos - rhusmos e skhêma que alguns autores equivocadamente tomam por sinônimos. Enquanto skhêma se refere à ekhô, "eu (me) tenho", "forma" fixa, realizada, posta de algum modo como um objeto, rhusmos, nos contextos em que aparece, concerne "a forma no instante que ela é assumida pelo que é móvel, fluido, a forma do que

27 TEOFRASTO, Causa das plantas, VI, VII, 2: 68 B 132 DK: anankê . . ta skêmata metarrhuthmizesthai.

28 SEXTO EMPIRICO, Contre les mathématiciens, VII, 137: 68 B 7 DK: eteêi ouden ismen peri oudenos, all' epirrhusmiê hekastoisin hê doxis.

29 Benveniste, E., Op. cit., p. 330.

30 Benveniste, E., Op. cit., p. 332.

31 Benveniste, E., Op. cit., p. 332. 
não tem consistência orgânica", isto é, "a forma improvisada, momentânea, modificável"32.

É assim que devemos compreender o uso que Demócrito faz do termo. Para ele, todas as coisas se constituem a partir dos agregados atômicos, de configurações particulares de átomos que, em razão de seus diferentes rhusmoi, dão origem a corpos distintos e particulares. E é por isso que rhuthmos, enquanto "maneira particular de fluir", foi o termo mais adequado a descrever as "disposições" ou as "configurações" sem fixidez e resultante de arranjos sempre sujeitos à mudança.

Entretanto, a interpretação proposta por E. Benveniste não é objeto de unanimidade. M. Serres, por exemplo, lhe reprova por não ter "nunca navegado em água doce" e o acusa de uma "falta de atenção ao real". Ele escreve: "Demócrito vê o ritmo onde ele se encontra, Benveniste não o viu "33. Isto quer dizer que se fixando no aspecto abstrato do termo ele teria negligenciado a dimensão da experiência real do ritmo, ou mesmo "sua própria realidade".

P. Sauvanet também, mesmo reconhecendo a contribuição "inegável" de E. Benveniste, pensa que convém nuançar seu artigo em dois pontos: primeiramente, diz que é preciso "reabilitar o sentido 'fluido' de rhuthmos, na medida em que, segundo o próprio Benveniste, 'a relação de rhuthmos com rheo não constitui em si mesmo causa de objeção'," e é preciso voltar, ainda, antes da época de Platão, avançada pelo linguista para " o nascimento do ritmo como retorno de parâmetro regular ou 'forma fixa', mesmo se é efetivamente com ele que o sentido evolui na direção daquele de metro ou de medida (metron) " ${ }^{34}$. Conclui-se que, para proceder a uma genealogia do conceito que desempenha um papel fundamental na física e na ética democritianas, é preciso conciliar a contribuição da linguística àquela da experiência vivida, como o sugere M. Serres. Vejamos, ainda, outras interpretações da noção de rhusmos em Demócrito.

\section{Outras interpretações}

V.E. Alfieri se interroga a propósito das razões que teriam levado Demócrito a empregar o termo rhusmos para designar a forma em lugar de

32 Benveniste, E., Op. cit., p. 333.

33 Serres, M., La Naissance de la physique dans le texte de Lucrèce. Fleuves et Turbulences. Paris: Les Éditions de Minuit, 1997, p. 190 : "La linguistique suit ici sans contradiction la pratique usuelle, la nature des choses, la théorie abstraite. Démocrite voit le rythme où il est, Benveniste ne l'a pas vu. L'irréversible d'Héraclite est rythmé çà et là par Démocrite, et tous les atomistes".

34 Sauvanet, P., Op.cit., p. 20. 
recorrer a skhêma ou morphê. A razão disso seria a faculdade que tem a função de designar qualquer tipo de movimento regular, aquele da dança tanto quanto aquele dos soldados em marcha, de significar a forma ou a configuração de objetos móveis ou mesmo estáticos (uma tropa, um caçador, as letras do alfabeto), e mais tarde a proporção, a justa medida, ou mesmo o estado de espírito $^{35}$. Alfieri discute a interpretação proposta por K. Von Fritz ${ }^{36}$, para quem o termo rhusmos

não representa como eidos o visível, isto é a forma como ela se apresenta aos observadores, mas a lei objetiva de conformação do objeto em si; e por isso ele representa a forma não em sua condição estática de coisa que veio a ser (in ihrem starren Gewordensein), como morphê = forma, mas a faz nascer de uma certa maneira no movimento fora dela mesma (sondern lässt sie gewissermassen aus sich selbst heraus sich bewegend entstehen).

K. Von Fritz e E. Benveniste se limitam a uma análise semântica do termo, sem precisar qual seria o fundamento de tal emprego. V. E. Alfieri, por sua vez, apresenta assim sua posição: no termo rhusmos os atomistas teriam provado a ressonância da ideia originaria de movimento no sentido de "adaptabilidade" ou "capacidade de agregação", em resumo a atitude bem determinada a se associar a outros átomos ${ }^{37}$. E propõe, então, que se traduza rhusmos por "medida" ou por qualquer outro termo capaz de dar a ideia de "forma" enquanto "forma geométrica" ou "dimensão".

Examinemos, agora, os testemunhos que o termo é empregado, tendo em vista esclarecer o sentido que lhe é o seu na lingua democritiana, prestando atenção ao aspecto do movimento que parece ter sido, segundo boa parte dos comentadores, a razao de ser da escolha deste termo.

\section{A nuance de movimento}

Diante de tal quadro de interpretações, tendemos a concordar com P. Sauvanet que o ritmo é "a forma que tomam os átomos em conjunção efêmera" ${ }^{38}$. Esta parece ser também a posição de M. L. Gemelli Marciano,

35 Alfieri, V.E., Atomos Idea. L'origine del concetto dell'atomo nel pensiero greco. Galatina: Congedo Editore, 1979 , p. $71-72$.

36 Von Fritz, K., Philosophie und sprachlicher Ausdruck bei Demokrit, Plato und Aristoteles. New York, 1939, p. 26.

37 Alfieri, V.E., Op. Cit., p. 73 : “'capacità d'aggregazione', ossia quella bene determinata attitudine ad associarsi con altri atomi che è in funzione della forma, secondo che questa sai uncinata, ricurva, spigolosa, ecc. (...)".

38 Sauvanet, P., Op. Cit., p. 43-44. 
para quem o rhusmos veicula uma imagem dinâmica: "o 'ritmo' é o passo cadenciado da dança e da marcha. Os poetas arcaicos o utilizam, pois, para indicar uma 'disposição' do ser humano em uma sequência mutável ou em uma variedade de estados de ânimo". Estas posições nos parecem interessantes porque conservam o dinamismo que comporta o termo do ponto de vista seja dos átomos considerados em sua individualidade e isoladamente, seja da ação dos átomos no interior dos agregados. Acreditamos ser possivel, por esta via, esclarecer um ponto que se encontra na origem de não poucas divergências entre os estudiosos. Trata-se da dificuldade em estabelecer se quando os atomistas falam de uma diferença de rhusmos, tem-se em mente os átomos considerados em sua singularidade ou os compostos atômicos. Ora, ao tomarmos rhusmos como a forma dinâmica delineada por um átomo no seu movimento natural, deveríamos admitir que ela concernisse os átomos individualmente, não sua substância ou aspecto fixo, mas sua maneira de ser, isto é a maneira com que se movem no vazio ou no interior de um agregado. Tal constatação nos incita, então, a examinar o conceito mesmo de movimento para poder compreender o movimento dos átomos e os rhusmoi que os distinguem em seu movimento.

Para Aristóteles, Demócrito teria sido o único a se interessar pela "maneira como se manifestam a alteração e o aumento nas coisas" 39 :

Demócrito e Leucipo, imaginando as figuras (poiêsantes ta skhêmata) dos átomos, explicam por essas figuras a alteração e a geração (tên alloiôsin kai tên genesin ek toutôn poiousi), a saber por sua dissociação e associação, a geração e a destruição, por sua ordem e sua orientação, a alteração. Mas como eles acreditavam que a verdade estivesse situada nas aparências, e como as aparências são contrárias e infinitamente variadas, eles imaginaram os átomos e as suas figuras em numero infinito (ta skhêmata apeira epoiêsan). Graças a esta hipótese, as mudanças em um objeto composto de átomos (tais metabolais tou sunkeimenou to auto) podem ter por efeito que o mesmo objeto apareça sob aspectos opostos a tal observador e a tal outro, e que um corpo muda (metakineisthai) se um corpo estrangeiro, mesmo pequeno, vem se misturar e aparece inteiramente mudado (metakinêthentos) se uma só parte muda de lugar; com as mesmas letras, com efeito, se pode compor uma tragédia e uma comédia. ${ }^{40}$

Esta passagem de Aristóteles ilustra bem a relação entre os rhusmoi dos átomos e a mudança ou transformação, uma vez que as diferenças entre os primeiros explicam a ocorrência dos processos observaveis nos compostos atômicos. Ele se serve de diversos termos para explicar a mudança: alloiôsis, metabolê, metakineisthai. Cada um deles tem em Aristóteles um sentido 
próprio que não parece, todavia, ter sido objeto de atenção por parte dos antigos atomistas. A argumentação de Aristóteles supõe conceitos que foram bem desenvolvidos na sua Física. Para ele todo movimento é mudança, mas não toda mudança é movimento, e a única mudança que pode ser considerada movimento é aquela que vai de um substrato a outro substrato (ex hupokeimenou eis hupokeimenon). E distingue, então, três tipos de movimento e de motor. 1) "Segundo a qualidade" (kata to poion), o "movimento de alteração" (kinêsis alloiôsis) cujo motor é "o alterante" (to alloioun) ; 2) "segundo a quantidade" (kata to poson), "o movimento de crescimento rumo à grandeza acabada" (auxêsis eis to teleion megethos) ou "diminuição partindo da grandeza acabada" (phthisis ek to teleion megethos) cujos motores são "o que faz crescer" (to auxon) e "o que faz diminuir" (to phthinon); 3) "segundo o lugar" (kata topon), "que não tem um nome próprio" (anônumos) - Aristóteles se refere a ele com o verbo pheresthai substantivado - é "o movimento local"/"transporte" (to pheresthai) cujo motor é "o transportante" (to pheron).

Demócrito não considerou com a mesma atenção e distinção que Aristóteles estas diversas categorias de movimento. O interesse de Demócrito se concentrava antes em descobrir e tornar evidente a natureza movente dos átomos e a estrutura dos compostos atômicos em sua predisposiçao à mudança. Ele pretendia, assim, dar conta da diversidade do real, da existência de corpos mais ou menos pesados, mais ou menos densos e, por conseguinte, mais ou menos propensos ao movimento - como é o caso da alma, constituída de átomos portando figuras as mais sutis, lisas e redondas -, ou ainda sua maior ou menor predisposição à mudança. Deste modo, a "forma dinâmica" (rhusmos) e o tipo de movimento a que diferentes rhusmoi predispõem os compostos nos quais se encontram circunstancialmente reunidos, permitem a Demócrito a formulação de uma hupothesis que torna possível, a um só tempo, oferecer uma resposta ao problema da unidade e da multiplicidade, e àquele do movimento e do relativo repouso, por meio de um principio que satisfaz à economia do real e do discurso sem destituí-los de sua inesgotável complexidade. Às exigências aristotélicas expressas no De caelo - "a Leucipo e a Demócrito, que afirmam que os corpos primeiros se movem sempre no vazio e no infinito, se deve pedir para precisar qual seja o seu movimento (tina kinêsin) e qual seja, portanto o seu movimento segundo à natureza (tis hê kata phusin auton kinêsis)" (De caelo III 2, 300 b 8) - e na Metafísica - "Com relação ao movimento (Peri de kinêseôs), de onde provenha e como advenha (hothen ê pôs huparkhei), também estes filósofos, analogamente aos outros, negligentemente passaram 
em silêncio ${ }^{41}$ - podemos dizer que, anacronicamente e graças aos próprios testemunhos de Aristóteles, os Atomistas as satisfizeram em termos. O movimento e o movimento segundo a natureza, nos remetem aos rhusmoi dos átomos. Se não nos forneceram as causas do movimento, segundo o próprio Aristóteles teriam dito que se movem porque não podem não se mover, dado o caráter inato de seu movimento. E, como diz Aristóteles, "não é oportuno buscar o princípio do que é eterno". Podemos concluir, então, que é através da noção de rhusmos que os Atomistas, e particularmente Demócrito, se empenharam em apresentar uma explicação para o movimento dos corpos simples - os átomos - no vazio e nos compostos, e para o movimento e a mudança dos corpos compostos, o conjunto dos aglomerados atômicos dotados de vida. 